\title{
Views and experiences on lockdown as a response to the prevention and control of COVID-19 crisis among residents of Uganda
}

Choolwe Muzyamba ( $\square$ Muzyamba@merit.unu.edu )

Universiteit van Amsterdam

Ogylive Mphanza Makova

AfriSight

Geofrey Mushibi

AfriSight

\section{Research}

Keywords: COVID-19, Lockdown, Uganda

Posted Date: April 27th, 2021

DOl: https://doi.org/10.21203/rs.3.rs-432060/v1

License: (c) (i) This work is licensed under a Creative Commons Attribution 4.0 International License.

Read Full License 


\section{Abstract}

Background: While lockdowns have become a gold standard response to the Covid-19 pandemic, debates on its usefulness still continue. There is currently good amount of research work originating from western countries on the usefulness of lockdowns, however, similar research is still missing in low income countries like Uganda which implemented stricter lockdowns. More importantly, not much is known about the views of the residents of Uganda for which such a measure was meant for. Despite the implementation of lockdowns, it is still not yet known how relevant residents of Uganda view the lockdown. Research has demonstrated that interventions are most successful when they resonate with the target population This study fills this identified gap by investigating the views and lived experiences of residents of Uganda with regards to the usefulness of the lockdown as a response to the prevention and control of COVID-19.

Methods: This was a cross sectional survey using qualitative methods of data collection. Data will was collected from 1000 participants in the four regions of Uganda on the views and experiences on lockdown as a response to the prevention and control of COVID-19 crisis among residents of Uganda. Data collection was down through use of a Qualtrics Survey Tool. Thematic analysis with the help of the Social representation theory was then used to analyze the data.

Findings: The study demonstrated that there was visible nuance in the manner in which the lockdown was characterized. On one hand it was seen as useful in slowing down the spread, protecting the fragile healthcare system and giving government enough time to learn about the novel virus and thus respond efficiently. On the other hand, our participants were critical of its devastative nature on the livelihoods of people. Particularly, the lockdown closed down economic survival opportunities for the most vulnerable in society, increased unemployment and poverty levels. The lockdown also contributed to worsening mental health conditions and simultaneously provided fertile ground for domestic abuse including sexual abuse especially among girls.

Conclusion: Ultimately, our study questions the narrow view of branding the lockdown as unequivocally good or bad. It rather sheds light on the complexities of its effect on society in Uganda by pointing out its multicapillary-like consequences in society wherein it can, in various ways protect lives and at the same time destroy livelihoods. Our study thus highlights that responding to such complexities defies the logic of implementing the lockdown as a 'one-size-fits-all magic bullet', but rather that it must be contextualized, localized and appropriated to the realities of Uganda.

\section{Background}

The coronavirus disease 2019 (COVID-19) was declared a global pandemic in March of 2020 by World Health Organization (WHO). COVID-19 is a viral disease that affects respiratory organs by causing inflammation of the lungs thereby constraining the carriage of oxygen in the blood to other organs of the body (Dorigatti, et al., 2020b). This can trigger pneumonia and the collapse of other vital organs of the 
body due to oxygen starvation. Research has shown that COVID-19 spreads through small respiratory droplets that can easily transfer the virus from one person to another (Ferguson, et al., 2020). As of December 2020, almost all countries in the world had reported cases of COVID-19. Different countries have responded differently to the pandemic with most resorting to lockdowns. A lockdown is an emergency protocol issued by the government with the purpose of preventing people from leaving a given area (The Economic Times, 2020).

Some scholars have lauded the introduction of lockdowns on grounds that they save lives by curtailing the spread of the virus (Dorigatti, et al., 2020a; Dorigatti, et al., 2020b; Dorigatti, et al., 2020c; Ferguson, et al., 2020). It has also been argued that lockdowns allow countries to 'buy time' which is important for guaranteeing appropriate responses to the pandemic (McCall, 2020). Lockdowns have been further credited for preventing the collapse of healthcare systems especially fragile ones (The Lancent Editorial, 2020). This pandemic presents risks to fragile healthcare systems that lack adequate bed-spaces, medication, staff and necessary medical equipment (Anderson, et al., 2020; McCall, 2020). Lockdowns are also seen as essential for 'flattening the curve' which simply means reducing the spread of the virus until a vaccine is discovered and made available to all (Hellewell, et al., 2020; Lipsitch, 2020).

While lockdowns are lauded by several scholars, they are also however criticized by others. Particularly, lockdowns are criticized for preventing the attainment of herd immunity something which was seen as essential in the absence of a known vaccine (Hammond, 2020; Giesecke, 2020). Lockdowns are also viewed as an impendent to people's livelihoods by intensifying socioeconomic situations of vulnerable people and for worsening mental health outcomes. Armitage and Nellums (2020) for instance highlight how lockdowns led to serious mental health problems among the elderly (Armitagea \& Nellumsa, 2020). This happened because lockdowns curtailed channels of social interaction among the elderly thereby leading to feelings of social isolation and loneliness. This combination was a good breeding ground for depression and anxiety (Armitagea \& Nellumsa, 2020). Lockdown measures also led to high rates of unemployment, reduced farming activities, closure of small business and distorted supply chains. The consequence of this is even worse among marginalized people (Alvarez, et al., 2020; Inoue \& Todo, 2020; McKibbin \& Fernando, 2020). It has also been shown that despite being well-intended, lockdowns produce negative externalities among children by stifling their education and interaction avenues thereby piling up potential child-related psychological disorders for the future (Choudhary, 2020; Singh, et al., 2020).

While there is good amount of research work originating from western countries on the usefulness of lockdowns, however, similar research is still missing in low income countries like Uganda which implemented stricter lockdowns. More importantly, not much is known about the views of the residents of Uganda for which such a measure was meant for. Despite the implementation of lockdowns, it is still not yet known how relevant residents of Uganda view the lockdown. Research has demonstrated that interventions are most successful when they resonate with the target population This study fills this identified gap by investigating the views and lived experiences of residents of Uganda with regards to the usefulness of the lockdown as a response to the prevention and control of COVID-19. 
Uganda makes a good case study because it is the country that implemented one of the strictest lockdowns in sub-Saharan Africa even before recording a single case of COVID-19 (Lirri, 2020). This included the closure of educational institutions representing a population of over 15 million students, having 14 days quarantine for returnees from abroad, restriction of travel to and from affected countries as well as a ban on public gatherings. Given the strict lockdown without enough corresponding assessment of its usefulness to the residents of Uganda, this study helps provide insights on this and could serve as a basis for evidence-based policy making on COVID-19 interventions in Uganda.

Theoretical framework

The Social Representation Theory (SRT) guided this study. This theory was first articulated and developed by Serge Moscovici in 1961 in which he provided insights on how social beliefs develop and evolve in society (Bauer \& Gaskell, 2008; Moscovici, 1961). The main aim of the theory is to demonstrate and assess the usefulness of various social phenomenon in society (Moscovici, 1961). Primarily, SRT postulates that a given phenomenon (or health intervention in this case) derives its relevance from a process of acceptance, assimilation and appropriation among members of society (Moscovici, 1998; Moscovici, 1961). More specifically, when a novel intervention such as a lockdown is prescribed for the first time in society, SRT holds that it must first undergo a process socially-acceptable and assimilation before it can be said to be useful. It first must be accepted, embraced and assimilated among the majority of the people in society. This is followed by people's assessments of its advantages and disadvantages regarding its intended purpose and to wider society. This process gives rise to two outcomes; one in which the intervention is positively characterized and another in which it is negatively characterized. The relevance of this intervention is thus viewed from this complexity (Moscovici, 1998). Therefore, the SRT was useful in providing complex insights on how lockdowns are useful or not to the residents of Uganda. The theory helped draw parallels that explain the various ways regarding in which lockdowns were seen to be either useful or not (Moscovici, 1998; Muzyamba, et al., 2015; Muzyamba, et al., 2018). Hence the SRT was used heuristically in this study to help provide guidance in the design, investigation, analysis, interpretation and presentation of our findings. The theory helped provide clear insights on the usefulness of the lockdown from the perspectives of Ugandans.

\section{Methods}

\section{Ethical consideration}

We obtained written ethical clearance from UVA IRB. Other than that, participants were thoroughly informed of the objectives of the study and asked to sign a written consent form before participating. For confidentiality purposes, the data was anonymized and securely stored on a computer.

\section{Study Design}

The study was a cross sectional qualitative survey. Informed by the SRT, data was collected on the views and experiences of lockdown among residents of Uganda. This study was conducted on a sample of 
Ugandan residents in all the four major regions of Uganda (Northern, Eastern, Western and Southern) via an AfriSight platform. This platform is computerized program developed by AfriSight to enable the mapping out of residents of Uganda drawn from the four regions.

\section{Sample selection}

The study participants were selected via the AfriSight platform. A stratified random sample selection technique was used. We randomly selected participants from all of Uganda's four regions. Adults who resided in Uganda during the lockdown were included and those who did not experience the lockdown were excluded from the study. The study constituted a sample size of 1249 participants. Our sample population varied in sex, educational levels, religious affiliation etc. See table 1 for summary of demographics.

\section{Table 1: Demographic data summary}




\begin{tabular}{|c|c|c|c|}
\hline Variable & Variable levels & Frequency & Percentage of total (\%) \\
\hline \multirow[t]{2}{*}{ Gender } & Male & 691 & 55.64 \\
\hline & Female & 551 & 44.36 \\
\hline \multirow[t]{4}{*}{ Marital status } & Single & 858 & 69.08 \\
\hline & Married & 366 & 29.47 \\
\hline & Divorced separated & 14 & 1.13 \\
\hline & Widowed & 4 & 0.32 \\
\hline \multirow[t]{2}{*}{ Are you religious? } & Yes & 1068 & 97.62 \\
\hline & No & 26 & 2.38 \\
\hline \multirow[t]{3}{*}{ Religious affiliation } & Christianity & 945 & 87.99 \\
\hline & Islam & 102 & 9.50 \\
\hline & Other & 27 & 2.51 \\
\hline \multirow[t]{3}{*}{ Education level } & Primary education \& below & 4 & 0.32 \\
\hline & Secondary education & 299 & 24.07 \\
\hline & Higher education & 939 & 74.65 \\
\hline \multirow[t]{3}{*}{ Source of income } & Employed & 383 & 30.84 \\
\hline & Running own business & 354 & 28.50 \\
\hline & Unemployed & 505 & 40.66 \\
\hline \multirow[t]{3}{*}{ Income per month } & Below 430, 000 Shillings & 843 & 67.87 \\
\hline & Between 430, $000-762,000$ & 240 & 19.32 \\
\hline & Above 762,100 Shillings & 159 & 12.80 \\
\hline
\end{tabular}

\section{Data collection}

Given the fact that COVID-19 pandemic made it impossible to meet our participants in person without risking their health, we collected the data using an online survey hosed by AfriSight. We used a Qualtrics Survey Tool (a software for data collection and analysis) to collect the data. Various questions were included, they ranged from knowledge of lockdown, adherence to lockdowns, perceived advantages of lockdowns, perceived disadvantages of lockdowns etc. A sample questionnaire has been attached as an appendix. This survey had to fit the complications presented by the COVID-19. Thus, instead of physically meeting people, we relied on collecting data electronically.

\section{Analysis}


As guided by the SRT, we used NVivo to analyze the data using thematic analysis technique. Thematic analysis technique is a system of analysis that works by building and organizing themes arising from the raw data. It systematically organizes, examines and summarize the data themes Therefore, in this study we made use of thematic analysis as guided by the SRT to develop themes deductively into two broad categories namely Positive characterization of lockdown and Negative characterization of lockdown. These broader themes were based on smaller building blocks which constituted summarized sub-themes of similar arguments as supported by exact quotes. This allowed us to clearly assess the various ways the lockdown was seen as useful or not.

Table 2: summary of qualitative results

\begin{tabular}{|c|c|}
\hline Global Theme & Codes \\
\hline \multirow{7}{*}{ Positive characterization } & Contained the spread of Covid19 \\
\hline & Helped prevent overwhelming the healthcare system \\
\hline & Reduced death rate \\
\hline & Helped in building of a coordinated response \\
\hline & Gave government time to prepare appropriate response \\
\hline & Helped improve personal hygiene \\
\hline & Helped in making people take Covid seriously \\
\hline \multirow{11}{*}{ Negative characterization } & Closed down money-making opportunities \\
\hline & Led to job loses \\
\hline & Led to bankruptcy \\
\hline & Led to closure of businesses \\
\hline & Increased poverty rates at household level \\
\hline & Increased levels of corruption \\
\hline & Worsened mental health outcomes \\
\hline & Reduced attention on other illnesses other than covid \\
\hline & Increased rates of domestic violence \\
\hline & Increased the risk of child and sexual abuse in households \\
\hline & Increased rate of underage pregnancies \\
\hline
\end{tabular}




\section{Results}

The SRT helped to guide the assessment of both positive and negative characterizations of the lockdown COVID-19 in Uganda. Experiences and opinions among our participants thereby demonstrating the complexity imbedded in lockdowns.

The majority of the respondents generally agreed that the lockdown slowed down the spread of COVID19. They seemed to have a general understanding that COVID-19 spreads through close contact with infected individuals as communicated by the Ministry of Health through various media channels such as radios, television and newspapers. They reported that COVID-19 was transmitted through close contact with infected people thus reduced person-to-person contact promoted via lockdowns was essential for prevention. Thus lockdowns were seen as a major factor responsible for the controlled transmission at the start of the epidemic in Uganda.

"Without lockdowns most people would have gotten infected and it would have been a catastrophe for the country. I am glad the lockdowns were implemented while we had few cases which really helped to apply brakes on the spread. I do not how it would have turned out without lockdowns"

Participant number 84

"It was necessary to prevent the spread of the deadly virus and thank god or government acted fast because without the lockdown we would have see a bad situation in the country" Participant 123

Respondents also pointed out that the lockdown prevented the collapse of the healthcare system in Uganda. Particularly, they were confronted with worries precipitated by media images of chocked healthcare systems in European countries such as Italy and Spain. Some respondents thus felt that the lockdown helped prevent a collapse of the healthcare system which they thought was already vulnerable given its already existing disease burden. The lockdown was seen as an obvious and inevitable protective measure to a weak healthcare system. This also meant that deaths resulting from COVID-19 were low.

"..now see, how countries with high income failed to prevent their hospitals from falling apart, what more our hospitals which already have fewer doctors and nurses. They would have obviously failed to cope with the rise in numbers of infected people. That's why I think lockdowns were important"

Participant 33

"It [lockdown] helped protect our healthcare system because I think it would have been a disaster had we not lockdown early enough and controlled the spread"

Participant 121

Some respondents highlighted that the lockdown especially within the first month, enabled the different sectors of the government led by the Ministry of Health to organize themselves to better understand the 
situation, prepare and plan for other response and control measures. They thus suggested that the lockdown promoted efficient coordination of activities by the COVID-19 response national task force at the start of the pandemic in Uganda.

"I think this is a complex task. Making sure that the response is effect relies heavily on the numbers being low so that there is proper and more efficient coordination and overall response. Lockdown allowed respondents to organize themselves and come up with a response strategy that was key in prevention of many deaths"

\section{Participant 78}

Lockdowns also served as a symbolic reminder of the seriousness of the pandemic and the need to maintain personal hygiene and observe social distancing. Lockdowns were accompanied by symbolic and literal signals of gravity of the pandemic. Thus our participants felt that the lockdown emphasized and continuously provided motivation to uphold necessary preventative measures which would have been ignored in the absence of the lockdown.

"being locked down somehow continuously reminded us of the seriousness of this pandemic. And it made people really take the measures seriously. People were maintaining hygiene such as constant washing of washing their hands, keeping their surroundings clean and observing social distancing" Participant

"Without the lockdown people would have been very laxed about upholding the measures. So the lockdown was a good motivating factor in forcing people to adhere to the measures and this is good because it helped prevent the infections from going of control"

Participant

While some respondents lauded the lockdown, others felt the lockdown was causing damage to their livelihoods. They reported a number of negative experiences resulting either directly or indirectly from the three months lockdown period in Uganda. Particularly, they highlighted the narrowing of incomegenerating corridors. It was especially emphasized that self-employed people particularly those operating small business had either a huge reduction in their income or completely shut down after going bankrupt. This mainly included vendors, shop, restaurant and hair-saloon owners. Since they largely depended on day-to-day sales to keep their businesses afloat and to maintain their livelihoods.

"This [the lockdown] was terrible for small business owners. With people locked down, small business owners either had no ability to make sales or they just couldn't get enough people to buy their products. And most families depend on such businesses for their upkept. So that is why small businesses went bankrupt, in debt or imply just closed down"

Participant

"Lockdown caused suffering to small businesses because it prevented them from operating normally. With a lot of people already unemployed int his country, it means that this lockdown destroyed many 
family businesses and could have worsened their situation"

Participant

Increased levels of unemployment were seen as a direct consequence of the lockdown. A considerable number of respondents reported losing their jobs as a result of the three months lockdown. They pointed out that this trend affected mostly those who worked for small business enterprises, however it wasn't limited to this group since some respondents who worked for bigger enterprises such as established hotels, supermarkets and even privately owned

"I lost my job I worked in a grocery store but now with everything lockdown, our shop couldn't raise money anymore and we had to close down and that's how I lost my ob. And I know a lot of people who are in the same situation. The people who are already poor are in bad shape right now"

Participant

"A lot of people lost their jobs. This has been a stressful period. Job loses are everywhere and I think the situation is yet to worsen. Even those looking for jobs are finding it extremely difficult now since a lot of small businesses are closing down. Job losses everywhere"

Participant

Respondents reported heightened levels of psychological stress as a result of isolations, increased unemployment and poverty levels. Several participants felt isolated and cut off from their usual social contacts leading to fillings of loneliness. It was also suggested that economic difficulties caused by the lockdown led to increased anxiety and worries especially because people to extent where Some respondents reported experiencing symptoms of depression.

"With this, I have no contact with my friends and workmates. Its just me and my partner and kids. I felt very depressed during the lockdown. This is not something I am uses to, I couldn't find ways to deal with $i t^{\prime \prime}$

\section{Participant}

"My biggest problem was stress. I didn't know where to get money to feed my family and this worried me a lot. How can people survive under such conditions. It was very difficult for me and many others because everything seemed to have just collapsed on."

Participant

Domestic violence was also seen as a consequence of the lockdown. In families, the respondents reported an increase in domestic violence and sited cases where the household heads were unusually physically and verbally abusive to them. Other respondents observed sexual abuse particularly of young girls increased during the lockdown. Many participants pointed out that there was a notable increase in the number of defilement and rape cases since the start of lockdown, the peak being towards the middle and end of the lockdown. Teenage pregnancies had risen in the country and many participants linked this to the lockdown. 
"Yes, lockdowns led to increased levels of sexual and physical violence in households. It is being reported everywhere about the rise of these cases because a lot of vulnerable girls and women are locked down together with men who are taking advantage of them".

\section{Participant}

"I think it can be seen from the raise in teenage pregnancies that something went wrong during the lockdown".

Participant

\section{Discussion}

The SRT helped to shed light on the complexity of the characterization of the lockdown as a response to the Covid-19 pandemic by residents of Uganda. While on one hand the lockdown was seen as useful, it also presented challenges unique to the realities of Uganda.

In support of the lockdown, our results indicate that it was characterized as necessary in curbing the spread of the virus and at the same time preventing an impending collapse of a healthcare system that was already under pressure from various other illnesses. The pandemic instigated fears of the potentiality of increased death toll especially considering the dominance of other comorbidities in the country that were believed to increase mortality. This means that slowing down the spread and protecting the healthcare system was served as a guiding principle within the general response. Further, the novelty of this pandemic precipitated a need for institutional-learning of the complexity of the virus (both in terms of spread and virulence). It also called for (re)-strategizing and the creation of an efficient response mechanism based on the lessons arising from on-going scientific knowledge production. To this regard, the lockdown provided the government with much-needed time and space to learn, develop effective institutional capacity and respond effectively. Some scholars have since credited the lockdown for the observed low incidence, prevalence and mortality rates that Uganda has seen during this pandemic (Nkengasong \& Mankoula, 202). There have also been consistent arguments in support of such measures coming from other parts of the world (Anderson, et al., 2020; Xiao \& Torok, 2020).

Conversely, our results also show that the lockdown was viewed as harmful to other aspects of life; particularly, it stifled already fragile economic lifelines for people especially those in the informal sector who coincidentally account for the larger share of the labor force in Uganda (WHO, 2017; Lirri, 2020). Several informal sector laborious in Uganda depend on uninterrupted daily hustles for survival and also live hand-to-mouth (Lirri, 2020). Thus the lockdown closed down avenues of such possibilities leading to loss of jobs, income and increased poverty levels. With the lack of financial support for struggling businesses and individuals in Uganda, the effect of the lockdown on the poor was worsened (Lirri, 2020). These findings are consisted with the evidence coming from other low income countries like Mozambique (FAO, 2021), South Africa (Bell, 2020) and India(The Lancent Editorial, 2020) in which similar consequences have been observed. Furthermore, the lockdown contributed to the worsening mental health of various people. This was due to the long-lasting periods of isolation which lacked a clear end 
date. This robbed people of much-needed human interaction central to the Uganda's cultural fabric. These findings are consisted with results coming from other studies specifically focusing on the effect of the lockdown on livelihoods in Africa (Burgess, 2020). Lastly, domestic and sexual abuse especially of young girls were said to have been ramped during the lockdown. Our results indicate an obvious and notable increase in the number of defilement and rape cases since the start of lockdown. It has been established by studies elsewhere which also come to the same conclusion that due to the fact that school closures cut down escape routes for most girls, they as a result find themselves stuck in homes where the perpetrators continue to abuse them without recourse (Baker, 2020; Keaveny, 2020).

In sum, our study shows the complexity of the lockdown in Uganda. It unveils the nuanced characterization of the effects of the lockdown by the residents of Uganda. It questions the notion of viewing public health interventions such as a lockdown as unquestionable goods or bads. As can be seen from our results, the lockdown in Uganda has been interpreted differently based on its multicapillary-like effect on society, wherein, it, on one hand helps protect lives and on another destroys livelihoods. This complexity must be factored in when creating such responses in order for them to have optimum outcomes. The lockdown provides opportunities and challenges that must inform policy makers in order for them to localize, contextualize and appropriate the lockdown to the realities of Uganda. Our study provides the first step towards achieving this by revealing these complexities.

\section{Conclusion}

With the help of the SRT our study set out to investigate the characterization of the lockdown as a response to the Covid-19 pandemic by residents of Uganda. The study demonstrated that there was visible nuance in the manner in which the lockdown was characterized. On one hand it was seen as useful in slowing down the spread, protecting the fragile healthcare system and giving government enough time to learn about the novel virus and thus respond efficiently. On the other hand, our participants were critical of its devastative nature on the livelihoods of people. Particularly, the lockdown closed down economic survival opportunities for the most vulnerable in society, increased unemployment and poverty levels. The lockdown also contributed to worsening mental health conditions and simultaneously provided fertile ground for domestic abuse including sexual abuse especially among girls.

Ultimately, our study questions the narrow view of branding the lockdown as unequivocally good or bad. It rather sheds light on the complexities of its effect on society in Uganda by pointing out its multicapillary-like consequences in society wherein it can, in various ways protect lives and at the same time destroy livelihoods. Our study thus highlights that responding to such complexities defies the logic of implementing the lockdown as a 'one-size-fits-all magic bullet', but rather that it must be contextualized, localized and appropriated to the realities of Uganda.

\section{Declarations}


Ethics approval and consent to participate

We obtained written ethical clearance from UvA IRB. Other than that, participants were thoroughly informed of the objectives of the study and asked to sign a written consent form before participating. For confidentiality purposes, the data was anonymized and securely stored on a computer.

\section{Consent for publication}

Not applicable.

\section{Availability of data and materials}

All materials relating to this study are provided

\section{Competing interests}

The author declares no competing interests

\section{Funding}

Afrisight and the Small Business Innovation Research (SBIR) - RVO.nl

\section{Authors' contributions}

CM provided leadership on all aspects of the study, while $\mathrm{CM}, \mathrm{GS}, \mathrm{OM}$ and $\mathrm{AO}$ also effectively contributed in carrying out the study including drafting the manuscript. All the authors read and approved the final manuscript.

\section{Acknowledgements}

Not applicable

\section{Abbreviations}

COVID-19 Coronavirus Disease 19

GNI Gross National Income

PSM Propensity Score matching

STR Social Representation Theory

UK United Kingdom

WHO World Health Organization 


\section{References}

Alvarez, F., Argente, D. \& Lippi, F., 2020. A Simple Planning Problem for COVID-19 Lockdown. University of Chicago- working paper.

Anderson, R. M., Heesterbeek, H., Klinkenberg, D. \& Hollingsworth, T. D., 2020. How will country-based mitigation measures influence the course of the COVID-19 epidemic?. The Lancent, 395(10228), pp. 931934.

Armitagea, R. \& Nellumsa, L. B., 2020. COVID-19 and the consequences of isolating the elderly. Lancet Public Health.

Baker, T., 2020. COVID-19 Aftershocks: Access Denied Teenage Pregnancy Threatens to Block a Million Girls Across Sub-Saharan Africa from Returning to School, s.I.: World Vision International.

Bauer, M. \& Gaskell, G., 2008. Social Representations Theory: A Progressive Research Programme for Social Psychology. Journal for the Theory of Social Behaviour, 38(4), pp. 1-19.

Bell, T., 2020. Actuaries warn Ramaphosa of a 'humanitarian disaster to dwarf Covid-19' if restrictive lockdown is not lifted. Daily Marverick.

Burgess, R., 2020. COVID-19 mental-health responses neglect social realities. Nature.

Choudhary, M., 2020. Lockdowns: Towards a Nuanced View. BMJ.

Dorigatti, I. et al., 2020a. Report 1: Estimating the potential total number of novel Coronavirus cases in Wuhan City, China, London: Imperial College.

Dorigatti, I. et al., 2020b. Report 2: Estimating the potential total number of novel Coronavirus cases in Wuhan City, China, London: Imperial colloge.

Dorigatti, I. et al., 2020c. Severity of 2019-novel coronavirus (nCoV), London: Imperial colloge.

FAO, 2021. Mozambique-Addressing the impacts of COVID-19 in food crises, Geneva: FAO.

Ferguson, N. M. et al., 2020. Report 9: Impact of non-pharmaceutical interventions (NPIs) to, London: Imperial College COVID-19 Response Team.

Giesecke, J., 2020. Lockdown-Free Sweden Had It Right, Says World Health Organization: Interview with Prof. Johan Giesecke, s.l.: American institute for economic research.

Hammond, J. R., 2020. SARS-CoV-2 Response: Imperial College Model and Lockdown Endgame. Foreign policy journal. 
Hellewell, J. et al., 2020. Feasibility of controlling COVID-19 outbreaks by isolation of cases and contacts. Lancet Global Health.

Inoue, H. \& Todo, Y., 2020. Propagation of the economic impact of lockdowns through supply chains. VOX CEPR Policy Portal.

Keaveny, P., 2020. Sexual and gender-based violence during COVID-19: lessons from Ebola, s.I.: The conversation.

Lipsitch, M., 2020. Will COVID-19 go away on its own in warmer weather? Center for Communicable Disease Dynamics (CCDD) at the Harvard T.H. Chan School of Public Health., Cambridge: Center for Communicable Disease Dynamics, Harvard T.H. Chan School of Public Health.

Lirri, E., 2020. How Uganda's tough approach to Covid-19 is hurting its citizens, Kampala: The Telegraph. McCall, B., 2020. Shut down and reboot-preparing to minimise infection in a post-COVID-19 era. The Lancent.

McKibbin, W. J. \& Fernando, R., 2020. The Global Macroeconomic Impacts of Covid-19: Seven Scenarios. Crawford School of Public Policy, Australian National University.

Moscovici, S., 1961. La psychanalyse, son image et son public. Paris: Presses Universitaires de France..

Moscovici, S., 1998. the history and actuality of social representations. In U. Flick (Ed) The psychology of the social. Cambridge: Cambridge University Press.

Muzyamba, C., Broaddus, E. \& Campbell, C., 2015. You cannot eat rights": a qualitative study of views by Zambian HIV-vulnerable women, youth and MSM on human rights as public health tools. BMC International Health and Human Rights, 15(26).

Muzyamba, C., Groot, W., Tomini, S. \& Pavlova, M., 2018. Community mobilization and maternal Care of Women Living with HIV in poor settings: the case of Mfuwe, Zambia. BMC Health Services, 18(155).

Nkengasong, J. N. \& Mankoula, W., 202. Looming threat of COVID-19 infection in Africa: act collectively, and fast. Lancet, 395(10227).

Park, A., 2020. The Time for Containment Is Over. Welcome to the Next Phase of Coronavirus, Time: New York.

Singh, S. et al., 2020. Impact of COVID-19 and lockdown on mental health of children and adolescents: A narrative review with recommendations. Psychiatry Res, 293(113429).

The Economic Times, 2020. What a coronavirus lockdown looks likes, and what you can do \& what you can't, New York: Economic Times. 
The Lancent Editorial, 2020. India under COVID-19 lockdown. 395(10233).

WHO, 2017. Primary health care systems (PRIMASYS): case study from Uganda, abridged version, Geneva: World Health Organization.

WHO, 2020. New WHO estimates: Up to 190000 people could die of COVID-19 in Africa if not controlled, Geneva: s.n.

Xiao, Y. \& Torok, M. E., 2020. Taking the right measures to control COVID-19. The Lancent .

\section{Supplementary Files}

This is a list of supplementary files associated with this preprint. Click to download.

- InterviewGuide.docx 